\title{
Face Masks may cause Visual Symptoms and Artifacts in Ophthalmic Patients
}

\section{Stephen Ocansey ( $\nabla$ socansey2@ucc.edu.gh )}

University of Cape Coast

\section{Yaw Akoto}

Our Lady of Grace Hospital, Ghana

\section{Carl Abraham}

University of Cape Coast

Obed Amoah-Smith

University of Cape Coast

Selassie Dzasimatu

University of Cape Coast

\section{Enyam Morny}

University of Cape Coast

Micheal Ntodie

University of Cape Coast

\section{Research Article}

Keywords: Corona Virus Disease, face mask, oculo-visual artifacts, symptoms, ophthalmic patients

Posted Date: April 21st, 2021

DOI: https://doi.org/10.21203/rs.3.rs-427405/v1

License: (c) (i) This work is licensed under a Creative Commons Attribution 4.0 International License.

Read Full License 
1 Face Masks may cause Visual Symptoms and Artifacts in Ophthalmic Patients

2 Stephen Ocansey, PhD, FAAO*; Yaw Osei Akoto, OD $₫$; Carl Halladay Abraham, OD, MSc*;

3 Obed Amoah-Smith, OD, FAAO+; Selassie Kojo Dzasimatu, OD*; Enyam Komla Amewuho

4 Morny, OD, $\mathrm{PhD}^{*}$, Michael Ntodie, $\mathrm{OD}, \mathrm{PhD}^{*}$

5 *Department of Optometry and Vision Science, School of Allied Health Sciences, College of

6 Health and Allied Sciences, University of Cape Coast, Ghana

7 "Eye Unit, Our Lady of Grace Hospital, Ekumfi Street, Asikuma, Central Region, Ghana

8 +University of Cape Coast Eye Clinic, Pioneer Rd, University of Cape Coast, Cape Coast

10 Corresponding author:

11 Stephen Ocansey

12 Current address of corresponding author: Department of Optometry, School of Allied Health

13 Sciences, College of Health and Allied Sciences, University of Cape Coast, Ghana.

$14 \quad$ Tel. +233203881939

15 Email: socansey2@ucc.edu.gh

16

17 Number of words: 2400

18 Number of Tables: 3

19 Number of Figures: 2

20

21 Acknowledgment

22 The authors are grateful to patients who agreed to that part in the study and the Staff at the

23 University of Cape Coast Eye Clinic and those at the Eye Clinic of Our Lady of Grace Hospital,

24 Breman Esikuma, all in the Central Region of Ghana. 
ABSTRACT

Purpose: To investigate the characteristics of mask wearing and the effect of masks on visual symptoms and clinical measurements in a sample of ophthalmic patients in Ghana.

Methods: A clinic-based cross-sectional descriptive study was conducted among ophthalmic patients who visited two primary care eye clinics in the Central Region of Ghana. Participants included 71 randomly sampled patients aged 18 years and above and consented to take part in the study. Their mean ages (SD) was $36.94 \pm 17.46$ and they were made up of 27(38\%) males and $44(62 \%)$ females. The patients responded to symptoms assessment questionnaire before their visual acuity (VA) for distance and near and IOPs with and without their face masks were measured.

Results: The majority 45(63.4\%) of the patients' used fabric masks and 25(35.2\%) reported ocular problems with the use of the masks. Of those who observed ocular problems, $8(32 \%)$ observed problems with the use of spectacles, and 5(20\%) also observed problems with their vision. The mean difference in distance VA with and without face mask for the right eye was

$420.08(0.36)$ and left eye was $0.05(0.25)$ MAR, indicating slight aberrations in vision. Mean

43 differences in measurements with and without face masks were not statistically significantly 44 different $(P<0.05)$. A higher proportion of persons wearing KN95 experience nausea or 45 headaches $(X=18.610, p<0.001)$ and discomfort of wearing of nose mask $(X=7.803, p=0.020)$. 46 None of those wearing a fabric face mask reported of difficulty in accurately reaching for objects 47 with the nose mask on. $(X=8.664, p=0.13)$.

\section{Conclusion}

49 Face masks may exacerbate oculo-visual symptoms in ophthalmic patients, which practitioners must pay attention to.

51 Keywords: Corona Virus Disease, face mask, oculo-visual artifacts, symptoms, ophthalmic 52 patients 
55 The newly identified coronavirus 2019 has caused the worldwide pandemic of coronavirus 56 disease 2019 (COVID-19). ${ }^{1}$ The novel virus, referred to as severe acute respiratory syndrome 57 coronavirus-2 (SARS-CoV-2) causes mild to moderate respiratory illnesses, and people who get 58 affected may recover without any specialized treatment. ${ }^{2}$ In the presence of co-morbidities such 59 as chronic heart disease, chronic respiratory disease, and diabetes, COVID-19 can be fatal. ${ }^{2,3}$

60 The virus primarily spread through respiratory droplets when an infected person coughs or 61 sneezes, and from discharges of the ocular mucosa surface or by indirect contact with virus62 contaminated surfaces. ${ }^{1,4}$ Unfortunately, no vaccines or medications have been formally 63 approved for the treatment of COVID-19, although some medications and vaccines are under 64 clinical investigation. ${ }^{5}$ Therefore, individuals and community adherence to the universal safety 65 precautions, announced by the World Health Organisation when it declared the COVID-19 66 outbreak as a pandemic on 30th January $2020^{6}$ is the only way to curtail the spread of the virus.

67 Examples of these universal safety precautions strategies being practiced include maintaining 68 personal hygiene, hand-washing behavior, social distancing, isolation and quarantine methods, 69 and use of personal protective equipment such as face masks. ${ }^{7-9}$

70 Further, the transmission of SARS-CoV-2 by asymptomatic individuals has been documented

71 and maximal shedding of the virus has been reported to occur in the early course of the illness. ${ }^{10}$

72 Therefore, health experts highlight the crucial role of wearing face masks in preventing

73 transmission. The use of face masks could, however, be most effective when compliance is high 74 among larger populations. ${ }^{11,12}$ This means the wearing of face masks have become the new 75 normal. Unwittingly, adherence to the wearing of face marks has had an impact on the physical, 76 mental, and social well-being of many people ${ }^{13}$. Many countries across the globe, including 
77 Ghana, have enacted legislation making it compulsory for individuals to wear face masks at 78 every social gathering including hospitals and clinics ${ }^{14,15}$. Recent survey conduct in Ghana 79 revealed that $82 \%$ of persons surveyed were using face masks. The same survey however found 80 that only $44.3 \%$ of those who have mask use them correctly. The incorrect use of a face masks

81 has implications ${ }^{16}$. Given that there is a possibility of contracting the virus through ocular 82 secretions, eye care practitioners and their patients are required to adhere to universal safety 83 precautions guidelines without compromise. This implies that ophthalmic patients, who may be 84 suffering from vision impairment and discomfort due to their conditions, now have to cope with 85 wearing a face masks during all clinical procedure ${ }^{17}$. There are reports that the wearing of 86 personal protective equipment, especially face masks if not worn properly can affect vision and 87 visual measurements through the introduction of oculo-visual artifacts ${ }^{7}$. Therefore, this study 88 investigated the possible impact of wearing face mask on vision and visual symptoms among 89 ophthalmic patients. The aim is to highlight the need to be aware of improperly fitted face masks 90 as a possible cause of an increase in patients' ocular symptoms and artifacts on standard ocular 91 measurements.

\section{Material and methods}

93 The study employed a clinic-based cross-sectional study design by recruiting regular ophthalmic 94 patients who reported to the Eye Clinics of two hospital facilities in the Central Region of 95 Ghana, that is, the University of Cape Coast Hospital and Our Lady of Grace Hospital, Breman 96 Esikuma during the period $20^{\text {th }}$ July to $3^{\text {rd }}$ August 2020, and following the lifting of lockdown 97 rules. 
Data were collected in two parts. First, questionnaires were interviewer-administered by

99 Optometrists to 71 randomly sampled ophthalmic patients who consented to participate in the study. All participants were 18 years and above and wore their face masks, while care was taken by researchers not to intervene in the manner the patients had fitted their face masks. The questionnaire contained questions on patients' demographics, type of face mask worn, and ocular symptoms experienced when wearing their face masks.

The second part involved optometrists measuring the patients' visual acuities for both distance and near visions, with and without their face masks on. Also, their intraocular pressures were measured during the slit-lamp examination of patients with and without their face masks on for each eye. All measurements were repeated twice and an average used. For visual measurements taken without face masks, patients were instructed to take their masks off briefly, 30 minutes after the initial measurement while the examiner wore their facemask and goggles under a transparent shield at all times. Examiners crosschecked to make sure that their face masks were 111 at all times properly fitted and did not interfere with measurements taken. The examination room 112 was frequently sanitized and ophthalmic equipment sterilized after each patient's examination. 113 Visual acuity measurements were recorded in LogMAR acuity and the intraocular pressure were 114 recorded in millimeters of mercury $(\mathrm{mmHg})$. LogMAR acuity measurements have been known 115 to be more sensitive when observing interocular differences in Visual acuity compared to other 116 visual acuity measures especially snellen ${ }^{19}$.

117 Data was recorded in Microsoft Excel spreadsheets (Microsoft Corporation, Redmond, WA, 118 USA) and cross-checked for accuracy. Statistical analysis will be performed using IBM SPSS 119 software, version 24 (IBM Corporation, Armonk, NY, USA). Descriptive statistics on sample 120 characteristics will be computed, including mean with standard deviation, and frequency 
121 distributions. A two-tailed t-test was used to determine mean differences (MD) in visual acuity

122 and intraocular pressure measures at a confidence interval of 95\%. LogMAR values were

123 linearised by converting them MAR to calculate the mean deviation from the "unlogged"

124 values. $P$-values $<0.05$ were considered to be statistically significant.

\section{Ethical approval}

126 The study involved only human subjects and adhered to the ethics of the 1964 Helsinki

127 declaration and its later amendments or comparable ethical standards. It was conducted without

128 violating the World Health Organisations ethical guidelines for research during public health

129 emergencies and also complied with all COVID-19 universal safety protocols. ${ }^{18}$ All procedures

130 performed in studies involving human participants were approved by the Institutional Review

131 Board of University of Cape Coast. All participants were fully informed about the nature of the

132 study, and informed consent was obtained from respondents. Verbal consent was sought from 133 participants to publish findings from the study.

135 Results

136 Demographics and use of face masks

137 Overall, 71 participants took part in the study, made up of 27(38\%) males and 44(62\%) females 138 as shown in Table 1. Their mean age (standard deviation) was $36.94 \pm 17.46$. While all the 139 patients wore a face mask in the clinic, slightly less $(97.2 \%)$ indicated that they wear face masks 140 at public places and only $1.4 \%$ reported additionally wearing face shields. Only a few $10(14.1 \%)$ 141 wore spectacles. The majority of the participants $45(63.4 \%)$ used fabric masks and $17(23.9 \%)$ 142 indicated using a combination of fabric and surgical masks for protection (Figure 1). For ocular 
143 symptoms, the majority $46(64.8 \%)$ of the patients didn't report any ocular problems experienced

144 whiles wearing face masks. Among those -25(35.2\%) - who reported problems with the use of

145 their face masks, some observed problems related to the use of their spectacles $8(32 \%)$ and $1465(20 \%)$ also observed problems with their vision. As shown in Figure 2, the most reported ocular 147 symptom by the patients to be associated with the use of their face mask were discomfort $14825(35.2 \%)$, blurry vision 20(29\%), poking around the eyes 19(27.1\%), excessive blinking and 149 tearing $12(17.1 \%)$ and headache-related symptoms $13(18.6 \%)$.

150 A higher proportion of persons wearing KN95 experience nausea or headaches $(X=18.610$, $151 \mathrm{p}<0.001)$ and discomfort of wearing of nose mask $(\mathrm{X}=7.803, \mathrm{p}=0.020)$. None of those wearing a 152 fabric face mask reported of difficulty in accurately reaching for objects with the nose mask on. $153(X=8.664, p=0.13)$. The association between symptoms reported and types of face mask worn 154 are shown in Table 2.

155

156

157 158 159 160 
163 Table 1: Demographics of the patients

\begin{tabular}{lll}
\hline Variable & & $\mathbf{N}(\mathbf{\%})$ \\
\hline Gender & Male & $27(38.0)$ \\
& Female & $44(62.0)$ \\
Age & $<18$ & $4(5.6)$ \\
& $18-35$ & $36(50.7)$ \\
& $36-55$ & $15(21.1)$ \\
& $56-75$ & $16(22.5)$ \\
Educational level & Tertiary/or higher & $26(36.6)$ \\
& Secondary/vocational & $23(32.4)$ \\
& Primary & $16(22.5)$ \\
& No formal education & $6(8.5)$ \\
\hline Total & & $\mathbf{7 1 ( 1 0 0 )}$ \\
\hline
\end{tabular}

165

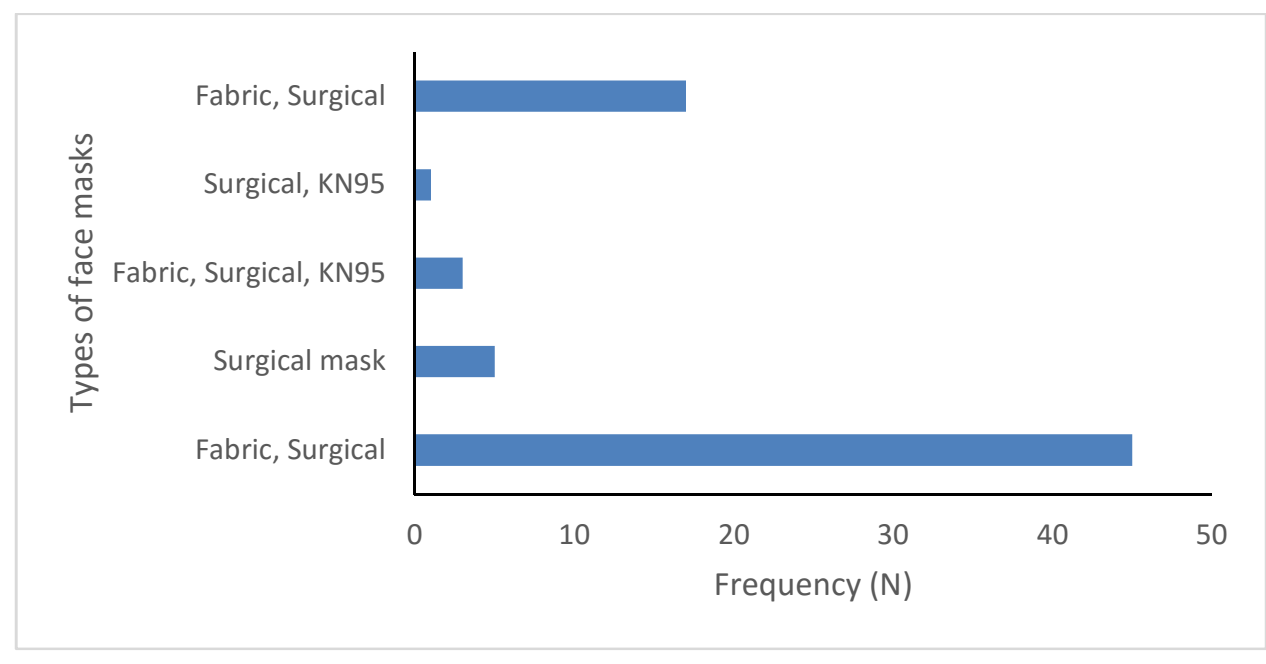




\begin{tabular}{|c|c|c|c|c|c|c|}
\hline \multirow{4}{*}{$\begin{array}{l}\text { Inaccuracy in reaching for an } \\
\text { item }\end{array}$} & & \multicolumn{4}{|c|}{ Type of face mask } & \multirow[b]{2}{*}{ p-value } \\
\hline & & Fabric & $\begin{array}{c}\text { Surgical } \\
\text { mask }\end{array}$ & KN95 & Total & \\
\hline & no & 45 & 20 & 3 & 68 & $.013 *$ \\
\hline & yes & 0 & 1 & 1 & 2 & \\
\hline \multirow{2}{*}{$\begin{array}{l}\text { Frequent squinting in order to } \\
\text { see }\end{array}$} & no & 44 & 20 & 4 & 68 & .796 \\
\hline & yes & 1 & 1 & 0 & 2 & \\
\hline \multirow{2}{*}{$\begin{array}{l}\text { Observe abnormal sensitivity to } \\
\text { light or dizziness }\end{array}$} & no & 42 & 19 & 3 & 64 & .447 \\
\hline & yes & 3 & 2 & 1 & 6 & \\
\hline \multirow{2}{*}{$\begin{array}{l}\text { Adopt an abnormal head } \\
\text { posture }\end{array}$} & no & 40 & 19 & 3 & 62 & .668 \\
\hline & yes & 5 & 2 & 1 & 8 & \\
\hline \multirow{2}{*}{$\begin{array}{l}\text { Unusual tearing or discharge } \\
\text { from eyes }\end{array}$} & no & 41 & 17 & 2 & 60 & .060 \\
\hline & yes & 4 & 4 & 2 & 10 & \\
\hline \multirow[t]{2}{*}{ Experience excessive blinking } & no & 38 & 17 & 3 & 58 & .858 \\
\hline & yes & 7 & 4 & 1 & 12 & \\
\hline \multirow{2}{*}{$\begin{array}{l}\text { Experience nausea or } \\
\text { headaches }\end{array}$} & no & 39 & 18 & 0 & 57 & $.000 *$ \\
\hline & yes & 6 & 3 & 4 & 13 & \\
\hline \multirow{2}{*}{$\begin{array}{l}\text { Poking of eyes or frequent } \\
\text { rubbing }\end{array}$} & no & 33 & 15 & 3 & 51 & .982 \\
\hline & yes & 12 & 6 & 1 & 19 & \\
\hline \multirow[t]{2}{*}{ Blurry vision } & no & 34 & 14 & 1 & 49 & .099 \\
\hline & yes & 11 & 7 & 3 & 21 & \\
\hline \multirow{2}{*}{$\begin{array}{l}\text { Discomfort with wearing of } \\
\text { face mask }\end{array}$} & no & 31 & 15 & 0 & 46 & $.020 *$ \\
\hline & yes & 14 & 7 & 4 & 25 & \\
\hline
\end{tabular}




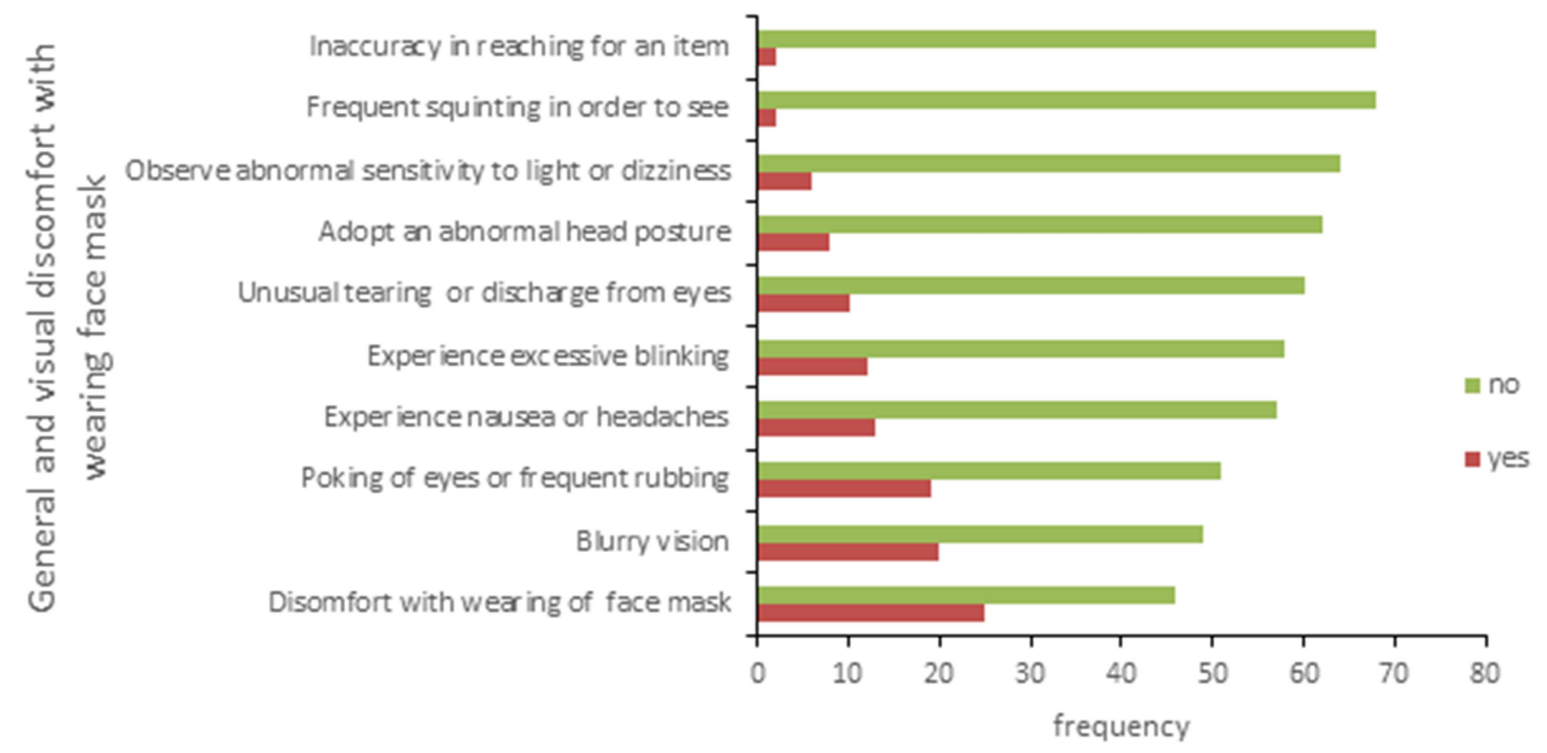

Fig 2: Reported oculo-visual symptoms associated with the use of face masks

\section{Measurements with and without face masks}

Differences observed between measurements with face masks on and without face masks on for visual acuity for the right eye and the left eye and intraocular pressure for the right eye and left and without face mask was $1.83 \pm 2.34$ and 1.78 \pm .2 .34 MAR respectively, while the mean near

182 visual acuity with a face mask on and without face mask for both eyes was $1.66 \pm 1.51$ and $1830.20 \pm 1.41 \mathrm{MAR}$ respectively. The mean difference in distance visual acuity with and without the 184 face mask for the right eye was $-0.08(0.36)$ and left eye was $-0.05(0.24)$, whiles the mean 185 difference in near visual acuity for the right eye and left eye was $-0.03(.10)$ and $-0.02(.10)$ 186 respectively, indicating slight aberrations in measurements with and without the face masks. The 
187 highest observed mean difference visual acuity was -0.08 MAR, which is one optotype 188 equivalent. ANOVA showed that the type of mask worn did not determine the change in Visual 189 acuity observed with and without the mask $(\mathrm{F}(2,88)=1.395, \mathrm{p}=0.255)$

190 The mean intraocular pressure with a face mask on for the right eye and left eye were 15.24 \pm 1912.91 and $14.82 \pm 2.99$ respectively, while the mean intraocular pressure without face masks for 192 the right eye and left eye was $14.86 \pm 2.70$ and $14.86 \pm 13.13$ respectively. Mean differences 193 observed for near visual acuity and intraocular pressure were statistically not significant (P-value $194<0.05)$.

195

Table 3: Measurements with and without face masks

\begin{tabular}{lcclccr}
\hline & $\begin{array}{l}\text { Habitual } \\
\text { Mean(SD) }\end{array}$ & $\begin{array}{l}\text { With Face } \\
\text { Mask } \\
\text { Mean(SD) }\end{array}$ & $\begin{array}{l}\text { Mean } \\
\text { Difference } \\
\text { (SD) }\end{array}$ & CI for MD & T & p-value \\
& & & & & & \\
\hline Distance VA RE(MAR) & $2.78(2.94)$ & $2.86(2.94)$ & $-0.08(.36)$ & $0.36-0.04$ & -1.84 & .071 \\
Distance VA LE(MAR) & $2.67(2.96)$ & $2.73(2.94)$ & $-0.05(.24)$ & $0.24-0.03$ & -1.76 & .082 \\
Near VA RE (MAR) & $1.73(0.64)$ & $1.76(0.65)$ & $-0.03(.10)$ & $0.10-0.03$ & -1.00 & .333 \\
Near VA LE(MAR) & $1.67(0.64)$ & $1.69(0.65)$ & $-0.02(.10)$ & $0.10-0.02$ & -1.00 & .332 \\
IOP RE (mmHg) & $14.86(2.70)$ & $15.24(2.91)$ & $-0.32(.02)$ & $-0.73-.08$ & -1.62 & .116 \\
IOP LE(mmHg) & $14.68(3.13)$ & $14.82(2.99)$ & $0.02(1.29)$ & $-0.48-.52$ & 0.07 & .942 \\
& & & & & &
\end{tabular}


199 Since the outbreak of COVID-19, healthcare professionals who come into contact with patients 200 at a close-range and their patients are required to mask up during clinical examination. Wearing 201 face masks is thought to potentially reduce the spread of the virus from person to contact by 202 reducing transmission of infected droplets. The face masks when fitted appropriately are 203 supposed to cover the mouth and nose of the wearer and the wearer must feel comfortable 204 without it pressing on the eye or affecting one's field of vision. However, if the face mask is not 205 constructed according to standards or appropriately maintained and fitted properly, it can cause 206 the wearer discomfort, disturbances in vision, and even incapacitate the person. ${ }^{20-22}$ For many 207 people, their main concerns and fears regarding wearing a face mask is breathing difficulties, but 208 not worn properly, disturbances in vision may affect their quality of life and have psychosomatic 209 implications.

210 Though the data from this study did not support the hypothesis that face marks may bias or skew 211 clinical measurements, as seen from the lack of meaningful differences in Table 2, and the lack 212 of statistical significance, the issue of wearing masks is certainly important in the context of the 213 COVID-19 pandemic. Masks present wearers with some challenges, and they are certainly a 214 challenge for society as revealed by the subjective symptoms reported by the sample patients 215 which deserves attention.

216 This study revealed that the most common face mask used by the patients was the fabric masks 217 type. Few patients used standardized face masks such as medical masks and respirators, possibly 218 because of cost implications and availability. ${ }^{12,20}$ The disadvantages of fabric face masks have 219 previously been documented. ${ }^{20-23}$ These include frequent touching, inability to change after a 220 single use, potential increased risk of self-contamination due to frequent touching of a face mask 221 and subsequently touching the eyes with contaminated hands. ${ }^{20}$ Others include potential 
222 headache and/or breathing difficulties and discomfort. ${ }^{20-23}$ Information on potential side-effects

223 of face mask on the eye is scanty. In a previous study, theatre staff who wears spectacles found

224 their spectacle lenses misting up on wearing a face mask due to air convection. ${ }^{22}$ In a recent

225 paper, Moshirfar ${ }^{21}$ and his colleagues reported a sharp increase in dry eye symptoms among

226 regular face mask users at multiple local clinics. Their paper indicated that the most reported

227 symptoms were ocular irritation, eye dryness, and vision-related problems. These symptoms

228 were more frequent in the elderly, immunocompromised, and health practitioners. It was

229 explained that increased airflow from the mask into their eyes likely accelerated the evaporation

230 of the tear film which, when prolonged, may result in ocular surface irritation or inflammation ${ }^{21}$.

231 In this study, the most reported eye problems by the patients to be associated with the use of face

232 mask were discomfort, blurry vision, poking around the eyes, excessive blinking and tearing and

233 headache-related symptoms. While these problems may be temporal, and only encountered with

234 the prolonged wearing of the mask, this study demonstrated that it created minor artifacts in

235 vision and ocular clinical measurements. The most likely explanation for the noise in

236 measurements obtained is the wrongful fitting of the face masks by the patients. Indeed, during

237 patients' examinations, it was observed that some patients had inappropriately positioned their

238 face masks, but examiners did not attempt to intervene due to the nature of the investigation. The

239 minor artifacts observed, is consistent with the subjective reporting of oculo-visual symptoms by

240 the patients, as indicated in Figure 2. Incorrect fitting of the masks likely creates air convection,

241 which causes expired air to flow from the mask into their eyes to increase tear film evaporation.

242 Other ocular problems reported such as squinting, inaccurately reaching for items, and abnormal

243 head posture (tilting the head to one side or moving forward or backward when viewing an item

244 of interest) may be due to the face masks interfering with the field of view. The reason espoused 
245 for findings here is in accordance with a study that assessed the use of face masks in a primary 246 care outpatient setting in Hong Kong, where nearly half of the participants (48\%) could not

247 demonstrated the correct steps in wearing a face mask. ${ }^{24}$ In Ghana, a population-based survey by 248 the Ghana Health Service indicated that more than $40 \%$ of those wearing masks did not fit them 249 appropriately ${ }^{16}$.

250 To the best of our knowledge, no study has been clinically reported on the introduction of ocular 251 artifacts in visual acuity measurements. In a recent study, researchers reported on some changes 252 observed with intraocular pressure measurements during the slit-lamp examination of patients 253 wearing filtering facepiece masks and N95 respirators. ${ }^{25}$ The errors were mainly attributed to the 254 greater dimensions of the masks in comparison with the surgical standard ones, and to the 255 presence of a pre-shaped rigid nose area that may have pressed against the Goldmann tonometer. 256 The lack of information may be attributed to the changing dynamics of the coronavirus disease, 257 making a balance between patient care, ethics, and research difficult. Whiles the changes 258 observed may not be clinically insignificant, for ophthalmic patients who may be already 259 suffering from visual discomfort, pain, and reduced vision, such temporal artifacts and increased 260 symptoms caused by prolonged wearing of face masks may compound their problem. 261 Nevertheless, looking at the current role of face mask in combating the spread of COVID-19, it 262 is worthwhile and wise for patients and practitioners to adhere to universal masking strategies. 263 However, during counseling, eye care practitioners should counsel and demonstrate to their 264 patients the proper way to fit and maintain their face masks. Before the commencement of 265 examinations, practitioners must crosscheck to make sure face masks are properly fitted on their 266 patients to avoid the introduction of noise in their measurements. 
267 Whiles this study is relevant for clinical practice and patient education, the application of the 268 results is limited by the small number of patients sampled, and the possible errors introduced by 269 examiners wearing face masks whiles taking the measurements despite the precautions taken.

270 We recommend further large-scale studies that involve a large number of subjects and designs 271 that will possibly expunge errors introduced by examiners face masks.

\section{Declarations}

\section{Funding}

274 The authors did not receive support from any organization for the submitted work.

\section{Conflicts of interests}

276 The authors also have no conflicts of interest to declare that are relevant to the content of this 277 article.

\section{Competing interests}

279 Authors declare no competing interest

280 Data availability

281 Data used for this study is contained in the manuscript and available from the authors upon 282 request.

\section{Author contribution}

284 All authors contributed to the study conception and design. Material preparation, data collection 285 and analysis were performed by Stephen Ocansey, Yaw Osei Akoto, Carl Halladay Abraham, 
286 Obed Amoah-Smith, Selassie Kojo Dzasimatu, Enyam Komla Amewuho Morny, and Michael

287 Ntodie . The first draft of the manuscript was written by Stephen Ocansey and all authors 288 commented on previous versions of the manuscript. All authors read and approved the final 289 manuscript

\section{References}

291 1. Zhu N, Zhang D, Wang W, et al. A Novel Coronavirus from Patients with Pneumonia in 292 China, 2019. N Engl J Med 2020;382:727-33.

293 2. Guan W, Ni Z, Hu Y, et al. Clinical Characteristics of Coronavirus Disease 2019 in 294 China. N Engl J Med 2020:1-13.

295 3. Wu F, Zhao S, Yu B, et al. A New Coronavirus Associated with Human Respiratory 296 Disease in China. Nature 2020;579:265-9.

297 4. Li Q, Guan X, Wu P, et al. Early Transmission Dynamics in Wuhan, China, of Novel 298 Coronavirus-Infected Pneumonia. N Engl J Med 2020.

299 5. Liu J, Cao R, Xu M, et al. Hydroxychloroquine, a Less Toxic Derivative of Chloroquine, 300 Is Effective in Inhibiting SARS-CoV-2 Infection in Vitro. Cell Discov 2020;6:6-9.

3016 WHO. Report of the Who-China Joint Mission on Coronavirus Disease 2019 (Covid-19). 302 Geneva; 2020.

3037 Aiello AE, Coulborn RM, Perez V, et al. Effect of Hand Hygiene on Infectious Disease 304 Risk in the Community Setting: A Meta-Analysis. Am J Public Health 2008;98:1372-81.

305 8. Qualls N, Levitt A, Kanade N, et al. Community Mitigation Guidelines to Prevent 
Pandemic Influenza — United States, 2017. MMWR Recomm Reports 2017;66:1-34.

307 9. Visentin LM, Bondy SJ, Schwartz B, et al. Use of Personal Protective Equipment during 308 Infectious Disease Outbreak and Nonoutbreak Conditions: A Survey of Emergency Medical 309 Technicians. Can J Emerg Med 2009;11:44-56.

310 10. Javid B, Weekes MP, Matheson NJ. Covid-19: Should the Public Wear Face Masks?

311 BMJ 2020;369:m1442.

312 11. Liu X, Zhang S. COVID-19: Face Masks and Human-to-human Transmission. Influenza 313 Other Respi Viruses 2020;14:472-3.

314 12. Howard J, Huang A, Li Z, et al. Face Masks Against COVID-19: An Evidence Review. 315 April 2020.

316 13. Alradhawi M, Shubber N, Sheppard J, et al. Effects of the COVID-19 Pandemic on 317 Mental Well-Being amongst Individuals in Society- A Letter to the Editor on "The Socio318 Economic Implications of the Coronavirus and COVID-19 Pandemic: A Review.” Int J Surg $319 \quad 2020 ; 78: 147-8$.

320 14. Serwaa D, Lamptey E, Appiah AB, et al. Knowledge, Risk Perception and Preparedness 321 towards Coronavirus Disease-2019 (COVID-19) Outbreak among Ghanaians: A Quick Online 322 Cross-Sectional Survey. PAMJ May 2020.

323 15. Dzisi EKJ, Dei OA. Adherence to Social Distancing and Wearing of Masks within Public 324 Transportation during the COVID 19 Pandemic. Transp Res Interdiscip Perspect 2020;7.

325 16. Lai THT, Tang EWH, Chau SKY, et al. Stepping up Infection Control Measures in 326 Ophthalmology during the Novel Coronavirus Outbreak: An Experience from Hong Kong. 
327 Graefe's Arch Clin Exp Ophthalmol 2020:1-7.

328 17. WHO. Ethical Standards for Research during Public Health Emergencies: Distilling

329 Existing Guidance to Support COVID-19. Ethical Stand Res Dur public Heal emergencies Distill

330 Exist Guid to Support COVID-19 R\&D 2020:1-4.

331 18. Elliott DB. The Good ( LogMAR ), the Bad ( Snellen ) and the Ugly ( BCVA, Number

332 of Letters Read ) of Visual Acuity Measurement. Ophthalmic Physiol Opt 2016;36:355-8.

333 19. WHO. Advice on the Use of Masks in the Context of COVID-19.; 2020.

334 20. Moshirfar M, West WB, Marx DP. Face Mask-Associated Ocular Irritation and Dryness.

335 Ophthalmol Ther 2020;9:397-400.

336 21. Malik SS, Malik SS. A Simple Method to Prevent Spectacle Lenses Misting up on

337 Wearing a Face Mask. Ann R Coll Surg Engl 2011;93:168.

338 22. Greenhalgh T, Schmid MB, Czypionka T, et al. Face Masks for the Public during the 339 Covid-19 Crisis. BMJ 2020;369.

340 23. Ho HS. Use of Face Masks in a Primary Care Outpatient Setting in Hong Kong:

341 Knowledge, Attitudes and Practices. Public Health 2012;126:1001-6.

342 24. Quaranta L, Micheletti E, Riva I, et al. Intraocular Pressure Measurement in Patients

343 Wearing Filtering Facepiece Masks. J Glaucoma 2020;29:999-1000. 
$347 \quad$ Figure Legends

348 Fig.1 Types of Face Mask used by the patients (Responses were not mutually exclusive)

349

350 Fig 2: Reported oculo-visual symptoms associated with the use of face masks

351

352 
Figures

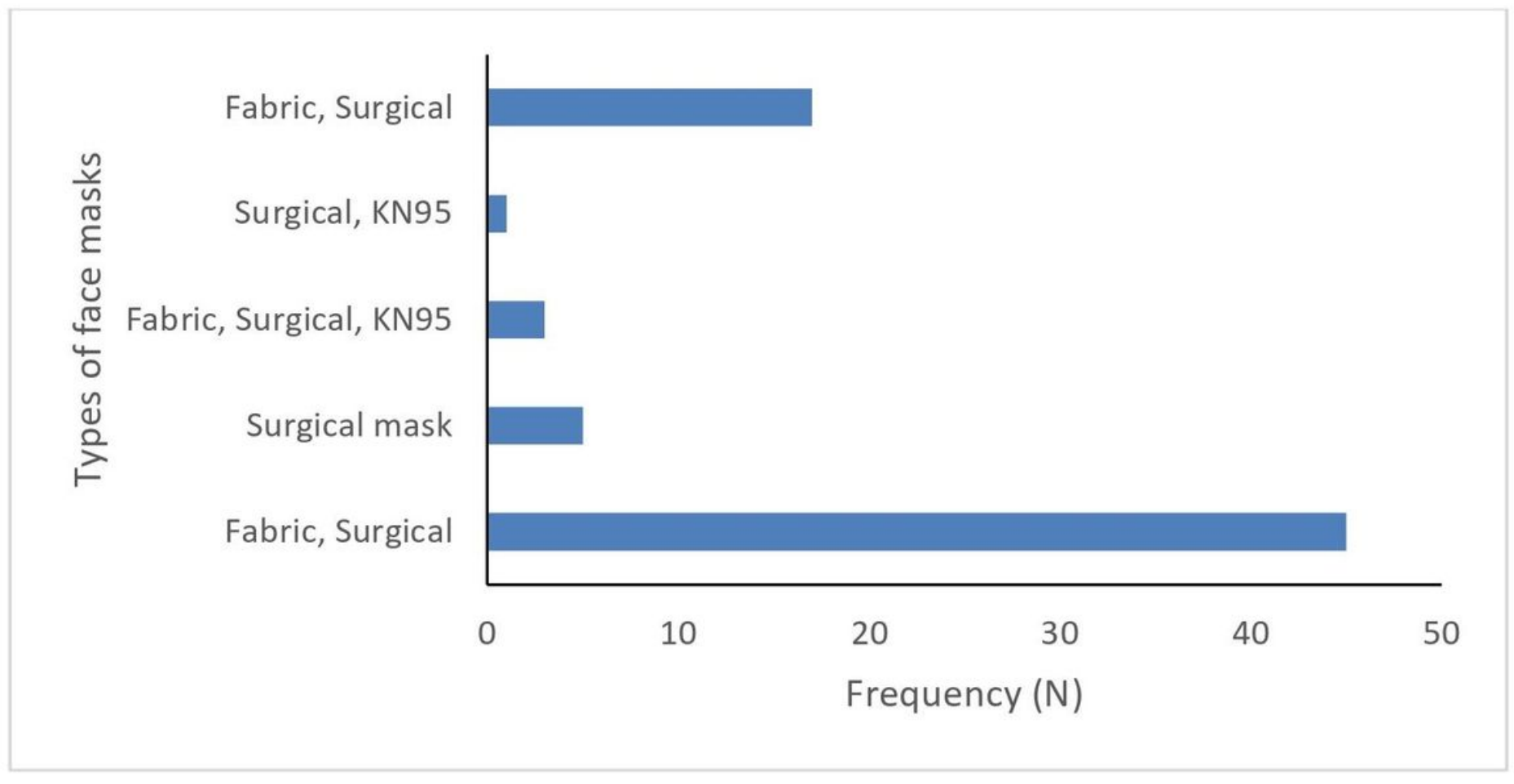

Figure 1

Types of Face Mask used by the patients (Responses were not mutually exclusive) 


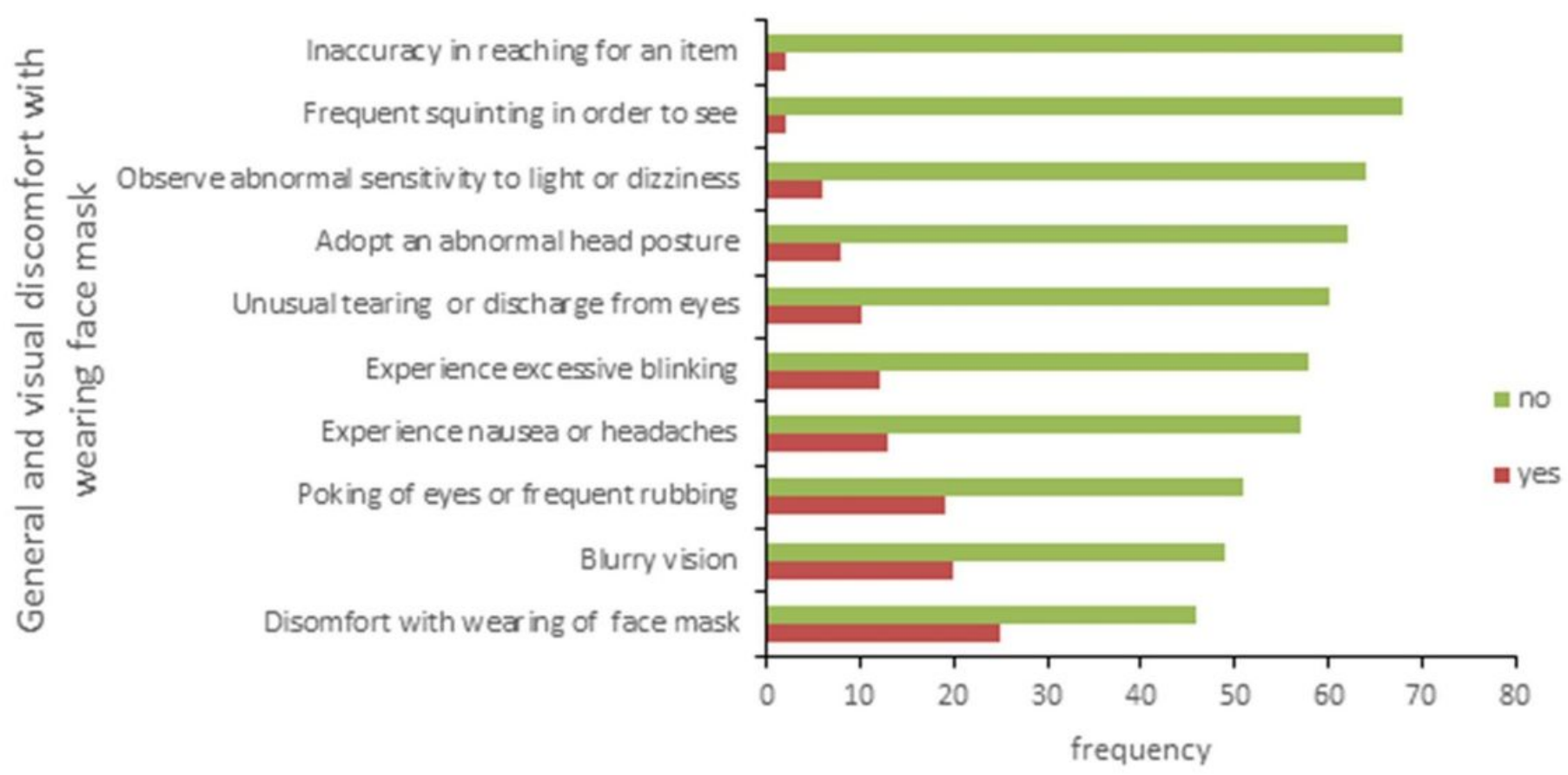

Figure 2

Reported oculo-visual symptoms associated with the use of face masks 